\title{
Akut Yas'ın Semptomatolojisi ve Yaklaşım *
}

\author{
Çeviren \\ R.Uslu
}

\section{GiRiş}

İk bakışta akut yas, medikal ya da psikiyatrik bir bozukluk olmaktan çok, acı verici bir duruma karsi veriten normal bir tepki gibi görünür. Ancak Psiklyatrist için sinıflandırilabilir nevrozlar olmasalar da travmatik yaşantılara verilen tepkilerin anlaşılması önem kazanmıştır. Yoksunluk veya sosyal etkileşimin birden kesilmesi gibi gunümüzde cok llgi çeken durumlar, psikosomatik bozuklukların başta gelen ruhsal otmenleri arasında yer almaktadırlar. Savaşta yitirdiklerinin yasın tutanların sayısındaki büyük artıs, benzer olayların toplumun ruhsal ve bedensel sağlığı uzerindeki olast etkisini bilmeyi gerekli kimaktadır.

Bü yazıda aşağıdaki konular üzerinde durulacaktır :

1. Akut yas, ruhsal ve bedensel belirtileri olan kesin sınırli bir sendromdur.

2. Bu sendrom bir kriz biçiminde ortaya çıkabilir, ertelenebilir, abartılabilir veya gizlenmiş olabilit.

3. Tipik sendrom yerine, her biri yas sendromunun farklı bir yanını simgeleyen saptır:lmı tablolar görülebilir.

4. Bu saptırım!s tabtolar, uygun tekniklerin kullanılması ile notmal bir yas reaksiyonuna dơnúştürülebilirler.

\section{Bizim çalışmamızda:}

1. Tedavi gördäkleri sırada bir yakınını yitiren psikonevrotik hastalar.
2. Hastanede olen hastaların yakinlar!.

3. Bir felaketten (Cocontst Grove yangıni) sağ olarak kurtulanlar ve yakınları ve,

4. Ordu mensuplarının yakınlarından oluşan 10 t kişi ele alınmıştır.

Bu araştırmada, bir dizi psikiyatrik görūsme yapılmış, içerik ve zamanlama kaydediłmiştir. Kayıtlar, klinik belirtiler ve ruhsal durumda görüşmeler boyunca gözlenen değişiklikler bakımından incelenmiştir. Göruş̧melerde psikiyatrist, hastanın belirtileri ve doğal tepkileri ortaya cikıncaya kadar tôm telkin ve yorumlardan kaçınmıştır. Bedensel yakınmalar, nesnel çalışmanın önemli göstergeleri olduğundan, spirogramlar (solunum Işlevi ölçúmleri), Gastrointestinal islevler ve metabolik işlevleri gösteren laboratuar calışma sonuçarı da kaydedilmiştir. Bu yazida yalnizca ruhsal alandaki gözlemlerimizi sunmak istiyoruz.

\section{NORMAL YASIN BELIRTILERI}

Akut yastaki insanların sergiledikleri tablolar dikkat cekici bir bicimde birbirine benzerler. Hepsinde ortak olarak, dalgalar biçiminde gelen, $20 \mathrm{dk}-1$ saat süren bedensel sıkıntı, boğazda sıkışa duygusu, karında boşluk duygusu, kas gücünde ve gerilim veya zihinsel ağrı olarak tantmlanan yoğun oznel acidir. Hasta bu huzursuzluk dalgalarının ziyaretler, öeni duşleme veya kendisine acınmasi gibi durumlarda artabilecegini ögrenir. Bedeli ne olursa olsun bu sendromdan kaçinma eğtitmi duyar. Reaksiyonun tetiklenebiliceği daşancesi ile ziyaretleri reddeder, ölenle ilgili tüm düşúncelerden kaçınmaya çalışır. Gơrüten en belirgin özellikter:

1. Iç çekme isteğinin artması: Bu solunum bozukluğ en cok yitirilenle ilgiti olarak konuşulduğunda olur.

\footnotetext{
* Lindemann, E: Symptomatology and management of acute grief. Am J. Psychiatry 101: 141-148, 1944.
} 
2. Güc yitimi ve yorgunluk: Evrenseldir ve şöyle betimlenir : "Merdiven çkmak neredeyse olanaksız." "Kaldırdığım her sey o kadar ağır ki." "En küçūk caba kendimi túkenmiş hissetmeme neden oluyor." "Kendimi tükenmiş hissetmeden kőşeye kadar yürüyemiyorum."

3. Sindirim lile ilgili belirtiler de şöyle betimlenir: "Yiyeceklerin tadı kum gibi,", "Hiç iştahım yok.", "Yemek yemem gerektiği için ylyecekleri tıkıyorum.", "Tükürügüum akmıyor.", "Karnımin Içi bos gibi.", "Midemde her şey yavaşılyor gibi."

Algılama genellikle değişir : Gerçeklik duygusu azalır, basska insaniardan duygusal olarak uzaklaşma isteği olur, nesneler gólgeli veya olduğundan kücük görülebilir ve ölenin hayali ile yoğun bir uğras vardır. Coconut Grove yanginında kızını yitiren bir hasta, kızının kendisini bir telefon kulübesinden aradığını sanıyordu. Adının kızı tarafından, kendisini rahatsız edecek kadar yũksek sesle söylendiğini duyuyordu ve bununla o denli uğraşıyordu ki, çevresini unutmuştu. Yakın bir arkadaşını yitiren genç bir pilot, onu düs ürünü bir arkadaş biçiminde canlı tutuyordu. Onunla yemek yiyor, sorunlarını konuşuyordu. Orneğin. Hava kuvvetterine katıma planını onunla tartışıyordu. Çalışmanın yapıldığı tarihe kadar, 6 ay boyunca arkadaşının artık onunla olmadığını yadsıdı. Yas tepkisinin bu ozelligi, bazı hastalar tarafından deliliğe yaklaşıklarının bir göstergesi olarak değerlendirilir ve kaygı yaratır.

Bir diğer önemli uğras alanı da suçluluk duygularını merkez alır. Yitirilen kişiye karşı ólümden önce yapilan yanlışar araştırılır. Kişi kendini, öleni ihmal etmlş olmakla suçar ve küçūk yanlışłar abartılır. Yangının ardından, genc bir kadın için başlıca konuşma konusu, ölen kocasının Coconut Grovéa bir tartışmanın ardından gitmiş olmasıydı.

Bunlara ek olarak, diğer insanfarla ilişkilerde sıcaklık duygusunun yitirilmesi, sinirlilik, öfke ile karşılık verme eğilimi, arkadaş ve akrabaların ilişkileri sürdürme çabalarına karşilık olarak rahatsız edilmeme isteği vardır.

Hastalar Için bu dūşmancıl duygular şaşırtıcı ve açıklanmaları güçtür. Yine delitiğe yaklaşımın işareti olarak degerlendirilirler. Bu duyguları denetlemek için büyük çaba harcanır ve sonuçta sıklıkla sosyal iliş̧ilerin resmi ve katı bir biçim aldığı görölür.

Kişinin günlük etkintikleri de önemli değişikliklere uğrar. Hareket ve konusmada azalma olmaz. Ozellikle olenden sóz edilirken konuşmanın arttığı gözlenir. Huzursuzluk, yerinde oturamama, amaçsız biçinde ortalıkta dolaşma ve sürekli yapacak birşeyler arama davranışları görülür. Aynı zamanda organize etkinliklerin başlatılması ve sûrdürülmesinde beceriksizlik vardır. Kişı gũnlük etkinlik düzenine sıkı sıkı sarılsa da etkinliklerinin her bir aşaması, özel bir görevmişcesine çaba harcanarak tamamianir. Eskiden, alışılagelen etkinliklerin büyük bölümünün ölen ile bağlantılı olarak yapıldığı ve artık anlamını yitirmis olduğu saskıniıkla tarkedilir. Ózellikle, arkadaşłarla buluşmak, sohbet etmek başkaları ile bazı girişimleri paylaşmak gibi sosyal alışkanlıkłar yitirilmiş gibidir. Bu durum kişinin kendisini ilişkilerde yüreklendiren ve aracı olan herhangi bir kimseye bağımłılığı lie sonuçlanır.

Yasta, aşağıdaki 5 belirti temeidir :

1. Bedensel sikıntijar.

2. Olenin hayafi ile uğraş

3. Suçluluk

4. Düşmancil tepkiler. yitirilmesi.

5. Alışlla gelmiş davranım ơrūntüterinin

Bunlara, patolojik tepkilerin sınırındakiler için tanımlayıcı olup diğerteri kadar gőze carpıcı olmasa da tüm tabloyu renklendiren bir 6 . belirti oklenebilir: Ölenin bazi özelliklerinin veya olümü neden olan olay sırasındaki davranışlarının yastaki kişide görülmesi. Kişi ölen babası gibi yürūdūğünü, aynaya baktığında yüzünün onunki gibi göründüğ̛ưnü düşünebilir.

Yoksunluğa uyumda psikiyatristin rolo bazt olgu ömekleri ile açıklanabilir:

"40 yaşında bir kadın, eşini yangında yitirmişti. Olay öncesinde iy bir uyum öykasü vermekte idi. 10 yaşında bir çocuğu vardı. Eşinin ólümānŭ duyduğunda ileri derecede çökmüş, acr acı ağlamıs, ölmeyi istemis, bu durumu üç gün kadar sürmúş̧ü.

Psikiyatrist lie gőrüşürken, yardım alacağı için hoşnut olduğunu, kocasının hayali ile acı veren bir ugraş içinde bulunduğunu ve aklını yetirmekten korktuğunu söylemişti. Hayalinde eşinin sabah işe gittiğini, sonra eşinin döndügouñū, kỏpekle oynadığını, çocuğunu kucakladiğını anlatmıştı. Eşinin başarının doruğunda îken çalısmafarını yarım bırakışını ve kendisine olan bağlılığını ayrıntıları ile anlattıktan sonra, artık bu yitimi kabul edebileceğini belirtmişti.

Daha sonraki görüsmelerde psikiyatriste nasıl bağlandiğını ve gổüşme saatini nasıl bektedigini dile getirmişti. Bu tepkiyi kocasına karşı vefasızlık olarak nitelendirmekle birlikte, yaşamında oluşan boşluğu doldurabileceğinin bir 
işareti olarak değerlendirmişti. Bunun ardından harekete gececek gũcũ bularak kendisini ve kızını gecindirmek için planlar yapmış, eski mesleği olan sekreterliğe dónmek için gerekli girisimlefi hesaplamiş ve uğras tedavisi bölümúnden, Fransızcasını geliş̧tirmek için yardım istemişti.

Hastanin hem duygusal, hem bedensel yakınmaları düzelmiş ve evine döndäŭünde uyum sağlaması kolay olmuştu."

"52 yaşında başarılı bir iş adami, mutlu bir evliliăi payiaştığı eșini yitimmişti. Baş edemediăgi siddetli bir yas içindeydi. Ziyaretçilerini görmek istemiyor, böylesine yikimıs olmaktan unatiyordu. Bedensel sağlığı taburculuğuna elvermekle birlikte, daha ileri yardım gereksindiği gerekçesi ile psikiyatri servisindeki yatıs süresini uzatmak istedi. Eşinden söz edildiğinde şiddetli cökkünlük belirtileri veren hasta, yavas yavas bu acı verici sürecten gecmeyi kabul ederek,3 gün içinde eve gidecek kadar iyileşme göstermişti.

Bu dönemde hastanın huzursuz olduğu, hızlt hiziı konuștuğu ve sŭrekli olarak birseyler ile uğraşmak istediği görülüyordu. Taburcu olur olmaz işe başlamış ve çok sayıda teletona yanit vermesinin gerektiği bir bölúme geçmişti. Ayrıca, amatör psikiyatrist rolünü benimsemis ve zamanının büyúk bir bölümünü, yakınını yitîmış olan başka birisine yardım etmek icin kulianmaya başlamıştı. Evini, mobilyasını ve ona essin animsatan herseyi satmaya karar vermiști. Uzun tartışmaların ardindan bu davranıslarının, yanlıs kararlar vermek pahasına yastan kaçınmak anlamına geldiğini görebildi. Yası ile daha doğrudan yüzleşmesi için desteklendi. Bu hasta sonradan oldukça iyi uyum yapmıştır."

Hastalarda 4-6 haftalık bir sürede, 8-10 görüșme ile komplikasyonsuz ve saptırilmamış bir yas tepkisi oluşturulabilmistir. Aynı bașarı, 13 Coconut Grove yangını kurbaninin 12'sinde elde ediimiştir.

\section{MORBID YAS TEPKILEAI}

Morbid yas tepkisi, normal yasın sapmıs bicimini anlatır. Morbid durumlar, "normal tepkilere" dönüşturüldükten sonra côzzüme ulaşabilmiştir. Morbid yas tepkileri şunlardır:

a) Gec lepkiler : En çarpıcı ve sık görülen durum, tepkinin gecikmesi veya ertelenmesidir. Kişi, önemli sorunlarla uğraştţ̆ı veya başka insanların moralininin yüksek tutulmasına hizmet etmesi gereken zamanlarda yitime karsı cok az tepki gösterir veya hiç tepki gőstermeyebilir.

"17 yaşında bir genc kız, yangında annesini, babasını ve erkek kerdeşini yitimişti. Akctğerteri ile ilgili ciddi sorunlar nedeni ile hastanede kaldığı süre içinde neşeli bir tavır göstermiš, yas belirtileri gözlenmemişti. Ulaincü haftanın sonunda taburcu edildiğinde neseli göruanüyor, hızls konuşuyor ve eve dönüp kendisinden kücăk iki kardeşine anababalık etmeye hevesli görünmekte Idi. Bu yassız kabullenme dönemi, eve gelenler dağılıp kardessleri de başka evlere yerleştirildikten sonra da sürdü. Ancak onuncu haftanın sonuna doğru, sık sık ağtama ve ölen anababayla ilgili uğraşlar ite seyreden gerçk yas kendini gösterdi." gecikmiş yas yiliarca sứrebilir. Yakın zamandaki bir ölümün akut yası içndeki hastalarda, yıllarca önce ölmūs bir kimse ile aşırı uğraş görülebillir.

38 yaşında bir kadının, annesinin ölümünü tepki vermediği, ancak 20 ył önce kolunun ampütasyonunu geciktirerek metastazlı kanserden ölen erkek kardeşi ile ilgili mutsuz fantaziler kurduğu görülmüstü. Akut yas nedeni ilegơrüşmeler yapilırken, eski yitimlerle ilgili sorular sorulduğunda pek çok hastada aynı durum ortaya çlkmıştır.

Aynı durumun değişik bir biçimde, hastanın yitirdiği kisinin ợüm yassina geldiğinde yas belirtisi geliştirdiği görülür. Örnę̆in 42 yaşındaki bir demiryolu isçisinin, açıklayamadiğı ama yas tepkisine iliskin olduğu kuşku götürmeyen belirtiler ile psikiyatrí kliniğine basvurdugunda, annesinin 42 yaşında intihar etmiş olduğu oğrenilmişti.

b) Saptirılmıs tepkiler: Gecikmis tepkiler, kişinin belirgin olarak normal dışı davranışlar sergilemediği, psikiyatriste başvurmasını gerektirecek ölçüde ciddi ve çarpicl olmasa da, günlük yaşamında görülen bazı değişikliklerln ardından gelişebilir. Bu değişiklikler, tanindiklarında basit ve kısa süreli psikiyatrik girişime yanıt veren çözümlenmemis yas tepkisinin yüzeydeki belirtileri olabilir. Bu beliftiler şöyle siniflandirilabilir :

1. Yitim duygusu olmaksızın aşırı hareketlijik: Zevk alma, kendini lyi hissetme hali görülür. Etkinllkler serüven nitelígi taşır. Ölenin sürdürdügüu etkinliklere benzer.

2. Ölenin son hastalı̆̆ının belirtilerinin ortaya c:kması: Boyle hastalar daha cok dahiliye kliniklerine başvurumlar ve sonuçta hipokondriasis veya histeri tanısı ile psikiyatriye gönderilirler. Fizyolojik işlevlerin ve varsa gerçek bulguların saptanmasi için ilerl araştırmalar gereklidir. Bir hastada, babasının olümünden iki hafta sonra başlayan ve üc hafta süren belirgin EKG degiş̧iklikleri bildirimmiştir.

Böyle "özdeșim" yolu ile belirti değiştirmek, konversiyon belittisi olarak kabul edilse de, kuşkusuz başka türlä bir bozukluk da sóz konusudur. 
3. Bir grup hastada, özellikle ülseratif kolit, romatoid artrit ve astum gibi psikosomatik belirtiler ortaya cıkar. Ulseratif kolitle ilgili bir çalısmada, $\mathbf{4 1}$ hastadân 33.'ünôn, hastalığin geliştiği dönemde önemli bir insanı yitirmis olduklari bulunmustur. Hastalardan ikisinin gittiklen cenaze törenlerinde kanlı ishal geliştirdikleri ŏğrenilmiştir. Diğerlerinde kolit, yitimin ardindan gelen birkac halta içinde başlamıştır. Yas tepkisi psikiyatrik tekniklerle cőzümlendiğinde, ülseratif kolitin gidiși de carpıc। biçimde düzelmiştir.

4. Sosyal uyum bozukjukları : Arkadas ve akrabalar ile ilişkilerde belirgin deģişiklikler ortaya cıkar. Hasta huzursuzdur, rahatsiz edilmek istemez, sosyal etkinlikjerden kacinır, arkadaşlarını eleştiriciliği ve ilgisizliği jle uzaklaştıracağından korkar.

5. Dũşmancıl bir tutum tüm ilişkilerde görülmekle birlikte, belirli kimselere karşı cok siddetli olabilir. Kişi, doktorları görevlerini inmal etmlş olmakla suçlar; gőrevlerini kőtüye kullanmıs olmalarından söz ederken, gerçek paranoid hastaların aksine suçladıkları kimseye yönelik saldirganik sergilemezler.

6. Yastaki kımselerin çoğu, kendilerine saçma gelen, kişiliklerindeki değişikłiği simgeledigini ve gizlenmesi gerektiğini düşundökleri dêsmancil duygular ile bas etmek için yoğun çaba gösterirler. Kimi bunu gizlemeyi basarsa da, duygu ve davranisları ile, sizofreniyi andıran biçimde kati ve resmi bír tutum sergilerler.

7. Hasta etkinliklerine dönmek için hevestidir, huzursuzdur hatta uyku uyumaz, ancak hiç bir etkinliği de kendi başına başlatamaz. Baskaları ile etkinlikleri paylaşinaktan hoşlansa da tek başına kararlar alamaz. Günlük etkinlikjer aşamalara bölünür ve her bir aşama böyük çaba harcanarak ve zevk almadan katedilir.

8. Hastanın sosyal ve ekonomik bakımdan kendisine zarar verici etkinliklere giriştiği görütebilir. Aşırı eli açıłık nedeni ile hastanın, sahip olduğu eşyaları başkalarına dağıttığı, yanlış parasal anlaşmalar yaptığı, "aptalca hareketler" nedeni ile arkadaslarini ve mesleki konumunu yitirdiği gözlenir. Böylesi kendini cezalandrrcı davranıslar, suçluluk duyguları ile ilişkilidir. Bu durum diğer aile bireylerini ve arkadaşları sıkıntıya sokar.

9. Yas tepkisi, gerginlik, ajitasyon, uykusuzluk, değersizlik duygusu, kendini suçlama ve cezalandirma istegl lie seyreden ajite depresyon ile sonuçlanabilir. Bu hastalarda intthar riski yüksektir.

"32 yaşında genç bir adam, küçük yanıklar ile olayı atlatır. Beşinci günde $\theta$ şininin öldūgüunü öğrenir. Esine ne olduğunu z̆grendiği için hafif bir rahatlama bile duyar ve hastanede kaldığı sure içinde dayanma gücẻ ile doktorunu etkiler. Taburculuktan bir süre sonra ailesi tarafından hastaneye getirilir. Eve döndükten sonra huzursuz olmuş, dinlenmek için akrabalarına gitmiş ancak, ove sikıntulı, korkulu, hiçbir organize etkinliğe yoğunlaşmama yakınmasi lie dönmüştür. Kliniģe yatırıldıktan sonra bu durumu sūren hasta ile görüşmek, tedavi ilişkisini kunup sưrdürmek güç olmuştur. Hasta aşırı gerginlik, nefes alamama, genel halsizfik, tükenme duygusu ve kendisine birşey olacağı kaygısı yaşamaktadır. Yangında, eşini çekip çıkarmaya çalışırken onun bayıldığını ve icerıde yandığ mı, kendisinin ise kalabalık tarafından dışarıya itilerek kurtulduğunu ögrenmiştir ve yogun bir suçluluk duygussu yaşamaktadır. Dört gün içinde ajitasyonu biraz yatışı; anlaşıldığını, suçluluk duygusu ve saldırganlık dürtúleriłle başa çıabileceğini dūsünmeye başlar. Altıncl gün, özel hemsiresinin dikkatini baska bir yöne cekip camdan atlayarak Intihar eder."

Hastanın inthar egifimi olmasa da, bedensel acı verecek bir yasantıyı gereksinebilir. Böyle hastalar sok tedavisi isteminde bulunabilirler." 20 aylık doğlu bir kaza sonucu boğulan 28 yaşindaki bir kadin hastada şiddetli bir ajite depresyon gelişir. Kendini suçlama, hiçbir şeyden zevk alamama, umutsuzluk, kocasına, ailesine ve psikiyatriste yönelik aşırı düşmancłl bir tutum sergllemektedir. Kendisine sok tedavisi yapimasında Israr etmis ve bu amacia başka bir doktora sevk edilmiştit. Şok tedavisine çok iyi yanıt vermiş ve suçlulutk duygusunun azlidiğını hissetmiştir"

Ajite depresyonlar, bizim çalışma grubumuzdaki yas tepkiterinin küçük bir bớlümünū oluşturmaktadır.

\section{PROGNOSTIK DEGERLENDIRME}

Yas tepkisinin tipi ve siddetl, bir älcujde önceden belirlenebilir. Obsessil kişilik ozellikleri olan ve daha önce depresyon geçirmiş hastalar, ajite depresyona adaydırlar. Küçôk çocukłarinı yitiren annelerde cok ağır bir yas tepkisi görülür. Ólen kimse ile, ölümünden önce kurulmus olan itiskisinin yoğunluğu da önem taşır. Bunun bir sevgi iliskisi olması gerekmez. Düşmantik, ozzellikle yeterince açı̆ga vurulmamış düşmanlık beslenen kimsenin ölümünô, düsmancıl dürtülerin belirgin olduğ́s şiddetli bir yas tepkisi Izleyebifir. Sıklıkia, ölenin bir sosyal sistemdekj anahtar kişi olduğu, olämün ardından o sosyal sistemin dağııdığı ve geride kalanların yasamında ve sosyal koşullarında büyūk değişiklikler oluştuğu görülür. Böyle błr duruma uyum yapmak, yitimle başetme zorunluluğunun üzerine eklenen zor bir görevdir. Bu etmenler, ölüm encesi dōnemde nevrotik 
belirtiler gösterme eğiliminden daha önemlidir ve önceki uyumu lyi olan kimselerde bije, en ağır morbid özdeşim biçimleri ortaya çıkabiliti.

\section{TEDAVI}

Uygun psikiyatrik yaklaşım lie bireyin sosyal uyumu düzenlenebilir, uzamıs ve ciddi değişiklikler onlenebilir. Psikiyatrist, hastantn ölen kimse ile olan bağlarından sıyrılmasına yardımc olmalıdır. Tedavide, yalnızca abartılı tepkilere değil, yeterince ortaya konamayan tepkilere de dikkai editmelidir. Böylece, gecikmis tepkilerin beklenmedik zamantarda ortaya çkarak, zarar verici olmaları önlenebilir.

Dini kurumlar, yastaki kimseye yardmda bôyük önem taşır. Hastanın ölen lie ilişkisinin sürmesi isteğini destekleyen inançları beslenir; "ilahi Takdir" kavrams ve gelecekte yeniden kavuşma inancı ite hastanın morbid suçluluk duygularınin yatışmasına yardımcı olur. Yine de, yalın avutma, hastanın yas ile başetmesi için yeterli bir yardım değildir. Hastanın, yoksunluğun verdiği acıyı kabul etmesi, ölen ile ilişkilerini gözden geçirmesi ve kendi duygusal tepkilerini tanıması gerekir. Delirme korkusu ve saşırtıcı duygusal değişikliklerin, özellikle düşmancil duyguların yarattığı korku ele alınmałıdır. Uzüntü ve yitim lie ilgilj duygular konuşuabilmelidir. Hastanın ölen kimse ile gelecekte kuracağı ilişki doşünülmeli, suçilutuk duyguları üzerinde durulmałı ve yeni iletişim örüntülerinin oluşturuimasında hastaya yardımcı olabilecek kimseler belirlenmelidir. Bütün bunlar 8-10 görūşme içinde yapulabilir.

Dũşmancil duygular yasın en betirgin özelliğl ise, özel teknikler gereklidir. Düşmanlık psikiyatriste yöneldiğinde eşlik eden yoğun suçluiluk duguları, hastanın ilerdeki görüşmeleri sürdürmesi için yüreklendirecek bir yakının varlığ gerekir. Gerginlik ve depressif belistiler cok tazla ise, günde iki kez benzedrin sülfat $5-10 \mathrm{mg}$. ve yatmadan önce sodyum amital $3 \mathrm{gr}$. başlanması yararlı olur. Tŭm psikoterapi girişimlerini başarısızlığa uğratan ağır ajite depresyonlarda, şok todavisinin yararı olabilir.

Yas tutan tüm insanlara, özellikle savaşlar sirasinda uzman psikiyatrist yardimı ulasamayacă̆ı için, diğer meslek gruplarının da eğjfimeleri gerekmektedir. Sosyal çaiş̧macılar ve din adamlari, görece normal tepkileri ele alılerken, riskli buldukları olguları psikiyatriste sevk edebilister.

\section{YAS BEKLENTISI TEPKILERI}

Çalısmamız başlangıçta gerçek oblume verilen tepkíler ile sınırl iken, yas tepkisinin ayrilmaya verilen tepkinin yainızca bir biçimi olduğunu góz önünde bulundurduk. Olüm son ayrılıktır ve geri dönülmez. Ayrilık başka nedenlere de bağlı olabilir. Böyle ayrılıklar sonrası tüm belirtileri ile bir yas tepkisinin gelişebilmesi şaşırtıcıdır. Ómeğin aile bireyterinden birinin onrduya katilması ile olan ayrılıklarda ölüm gerçekleşmese bile, tendidi sürer. Yas beklentisi olarak adlandırdığımız bu sendroma bugüne dek gereken önem verilmemiştir. Hasta, babası ya da oğlunun olası olümünden sonraki uyumu îte o denli ilgilidir ki, yasın tüm aşamalarından (depresyon, ayrıan kimse ile aşırı uğraş, ayrilanın başına gelebilecek tưm ölüm biçimlerinin gözde geçirilmesi ve buna uyum sağlayabilmek için kendisinin yapması gerekenler) geçer. Bu tepki kişiyi ani ölumün etkisine karşı korursa da, yeniden bir araya gelindiğinde olumsuz sonuçlar yaratabilir. Bir asker savaştan dōndügüunde, karısı onu artık sevmediğini ve hemen boşanmak istediğini seylemişti. Böyle durumlarda yas süreci tatamlanmış, kişi bağlarından sıyrıımıs ve yeni etkileşimlere uyum sağlamaya hazırlanmıştır. Koruyucu önlemler ile bu tür aile içi sorunlarin önüne geçilebilir.

\section{BIBLIYOGRAFYA}

Bu gözlemlerìn çoğu yeni değildir. Gecikmiş tepkiler Helene Deutsch tarafından betimlenmiştir. Myerson yakın zamanda yoksunluk sonucu gelişen ajite depresyonlarda şok tedavisini öne sürmũştür. Morbid özdeşim, hem psikoanalitik literütürde pek çok çalłşmada, hem de yakın zamanda H.A.Murray taraiından vurgulanmıştır. Yas ile depressif psikozlar arasındaki ilişki Freud, Melanie Klein ve Abraham, tarafindan tartışılmıştır. Savaş sırasındaki yoksuntuk tepkileri Wilson tarafından anlatılmıştır. Coconut Grove yangınına tepkiler, bu konuyu ele alan bir monografinin bir bölümünde tartışıımışłardir. Roserbaum, savas sırasındaki ayrılıkların tepkisini açıklamıştır. Astım ve romatoid artritin ruhsal etmenleri arasında yas tepkilerinin yerini Cobb ve ark. vurgulamışlardır.

\section{KAYNAKLAR}

Deutsch, H. (1937) Absence of griet. Psychoanalyt.Quart, 6:12.

Myerson, A. (1944) The use of shock trepy in prolonged grief reactions, New England, J.Med. 230.9, Mar. 2.

Murray,A.A; (1937) Visual manifestations of personality Jr. Abn. \& Social psychol. $32: 161-181$.

Freud, S. Mourning and melancholia Collected Papers N, 288-317; 152-170. 
Klein, M. (1940) Molurning and its relation to manic-depressive states. Internat. J. Psychoan. 215: 125-153.

Abraham, C. Notes on the psycho-analytical investigation and treatment of the libido, view in the light of mental disorder. Selected Papers.

Wilson, A.T.M.; Reactive emotional disorders, Practitioner, $146: 254-258$.

Cobb, S. \& Linderman, E. (1943) Neuropsychiatric observations after the Cocoanut Grove fire. Am. Surg.

Aosenbaum, M. (1944) Emotional aspects of wartime separations. Family, 24 :337-34t.

Cobb,S.; Bauer, W.; and Whitney, I. (1939) Emironmental factors in rheumatoid arthritis. J.A. M.A. $113: 668-670$.

McDenmott, n.; and Cobb,S. (1939) Psychogenic factors in asthma. Psychosom. Med. 1:204-341.

Lindermann, E.; Psychiatric factors in the treaiment of ulcerative colitis. In press. 